Subscriber access provided by Caltech Library

\title{
Communication
}

\section{Alternate heme ligation steers activity and selectivity in engineered cytochrome P450-catalyzed carbene transfer reactions}

Kai Chen, Shuo-Qing Zhang, Oliver F. Brandenberg, Xin Hong, and Frances H. Arnold

J. Am. Chem. Soc., Just Accepted Manuscript • DOI: 10.1021/jacs.8b09613 • Publication Date (Web): 29 Oct 2018

Downloaded from http://pubs.acs.org on October 30, 2018

\section{Just Accepted}

"Just Accepted" manuscripts have been peer-reviewed and accepted for publication. They are posted online prior to technical editing, formatting for publication and author proofing. The American Chemical Society provides "Just Accepted" as a service to the research community to expedite the dissemination of scientific material as soon as possible after acceptance. "Just Accepted" manuscripts appear in full in PDF format accompanied by an HTML abstract. "Just Accepted" manuscripts have been fully peer reviewed, but should not be considered the official version of record. They are citable by the Digital Object Identifier (DOI®). "Just Accepted" is an optional service offered to authors. Therefore, the "Just Accepted" Web site may not include all articles that will be published in the journal. After a manuscript is technically edited and formatted, it will be removed from the "Just Accepted" Web site and published as an ASAP article. Note that technical editing may introduce minor changes to the manuscript text and/or graphics which could affect content, and all legal disclaimers and ethical guidelines that apply to the journal pertain. ACS cannot be held responsible for errors or consequences arising from the use of information contained in these "Just Accepted" manuscripts. 
Cytochromes P450, a class of heme-dependent proteins, natively function as oxygenases and transfer oxygen to hydrocarbons or heteroatoms. ${ }^{1,2}$ Our group and others have repurposed P450s to perform non-natural carbene- and nitrene-transfer reactions. ${ }^{3-5}$ In the presence of diazo reagents as carbene precursors, iron-carbenoid intermediates can form in the enzyme active site and enable carbene addition to unsaturated carbon-carbon bonds ${ }^{6}$ or insertion into heteroatom-hydrogen bonds. ${ }^{7}$ Until now, these catalysts have accepted a narrow set of diazo reagents (e.g., ethyl 2-diazoacetate), ${ }^{6}$ which limits the structural diversity of the products. In addition, mechanistic profiles of carbene insertion into $\mathrm{X}-\mathrm{H}$ bonds (e.g., $\mathrm{X}=\mathrm{S}$ ) remain underexplored, ${ }^{8}$ which has impeded further development. Exploration of biocatalytic scenarios using structurally diverse carbenes together with mechanistic studies would significantly expand the synthetic value of these methods and aid our understanding of how the enzyme scaffold promotes high catalytic efficiency and selectivity.

Lactones are an important class of organic moieties with applications in synthetic chemistry, ${ }^{9}$ materials science ${ }^{10}$ and medicinal chemistry. ${ }^{11} \mathrm{~A}$ few studies have demonstrated that $\alpha$ diazo lactones can be utilized by rhodium complexes for carbenetransfer reactions. ${ }^{12}$ However, these rhodium-carbenes are prone to $\beta$-hydride migration, ${ }^{13}$ which gives rise to undesired unsaturated lactones; optimization of the rhodium catalysts and cryogenic reaction conditions are required to attenuate these side reactions. ${ }^{12 \mathrm{a}}$ Additionally, no enantioselective versions of these transformations have been reported. Our previous work on engineering hemeproteins for transfer of acyclic carbenes highlighted the power of directed evolution to shape protein active sites and greatly improve both reactivity and selectivity. ${ }^{6 \mathrm{a}-\mathrm{e}} \mathrm{We}$ therefore speculated that aptly engineered hemeproteins would be capable of generating

and stabilizing lactone-carbene intermediates, circumventing unwanted $\beta$-hydride migration, and facilitating subsequent carbene-transfer reactions with exquisite stereocontrol. This proposed enzymatic approach would provide a concise route to a broad array of lactone-containing products.

We initially focused on constructing cyclopropane-containing spiro-lactones using $\alpha$-diazo- $\gamma$-lactone (LAD) and styrene (1a) as substrates. Transfer of a cyclic carbene to an olefin double bond is expected to form a spiro-carbon center. Quaternary stereogenic centers frequently occur in biologically relevant molecules and medicinal compounds, ${ }^{14}$ but are challenging to make due to the highly congested nature of these centers. ${ }^{14,}{ }^{15}$ Moreover, the anticipated reaction produces a strained, three-membered ring and furnishes two chiral centers in a stereoselective manner, which necessitates precise control of the three-dimensional orientation of two coupling partners. We believe this is a good challenge for an enzyme catalyst.

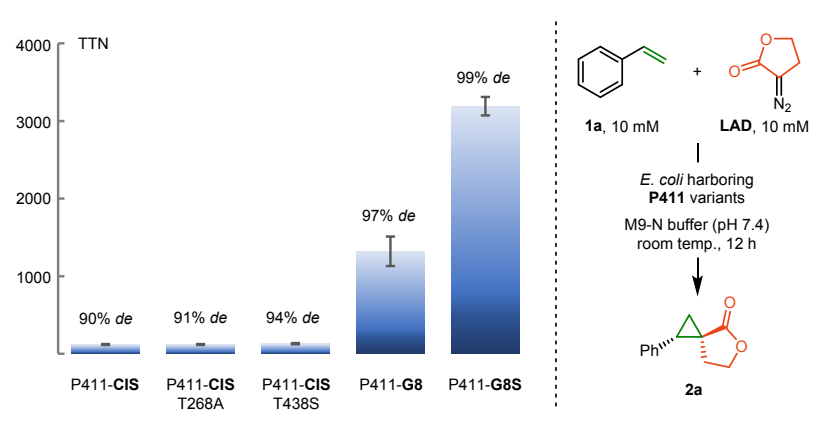

Figure 1. Comparison of P411 variants for forming spiro[2.4]lactone 2a. Reactions were performed in quadruplicate: suspensions of $E$. coli expressing P411 variants $\left(\mathrm{OD}_{600}=30\right), 10$ $\mathrm{mM}$ 1a, $10 \mathrm{mM}$ LAD, $25 \mathrm{mM}$ D-glucose and 5 vol\% EtOH in M9-N buffer at room temperature under anaerobic conditions for 12 hours.

We began by testing a panel of cytochrome P411 (Ser-ligated P450) variants, expressed in Escherichia coli (E. coli) and used as whole-cell catalysts, with LAD and 1a as substrates (Figure 1). Variant P411-CIS, ${ }^{16}$ previously engineered to react with ethyl 2diazoacetate and transfer the corresponding $\alpha$-mono-substituted carbene to styrene to forge a cis-cyclopropane, showed modest reactivity towards spiro-lactone formation, with $120 \pm 10$ total turnovers (TTN) and 90\% de. Several P411 variants with various active site mutations (e.g., T268A or T438S) were tested but did not exhibit substantial improvements in activity (Figure S1). 
However, to our delight, P411-CIS double mutant L437F T438Q (referred to as P411-G8), previously evolved for carbene transfer to heteroatom-substituted olefins, ${ }^{17}$ was found to have 10 -fold higher reactivity, providing $1320 \pm 190 \mathrm{TTN}$ while also showing improved stereoselectivity $(97 \% \mathrm{de})$. A variant with two additional mutations, L75Y and L181I (referred to as P411-G8S ${ }^{18}$ ), was an even better biocatalyst, furnishing the desired spiro-lactone product 2a in $3090 \pm 120$ TTN, $99 \%$ de and $>98 \%$ ee. Control experiments showed that free heme does not catalyze this reaction.

To examine whether the serine axial ligand of this P411 variant played a significant role in promoting in vivo cyclopropanation activity, we mutated serine back to the canonical P450 axial ligand cysteine and found that the resulting P450-G8S variant synthesized 2a with much lower activity $(380 \pm 20$ TTN) but the same stereoselectivity (Figure S2).

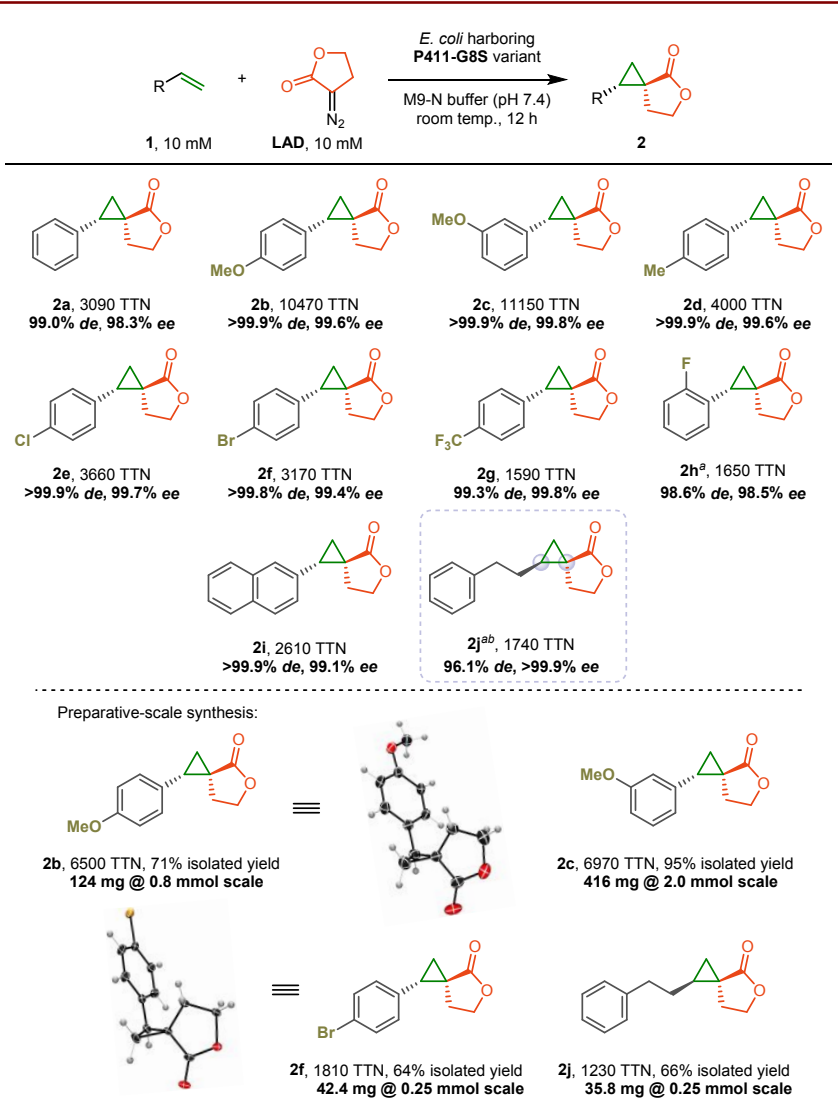

Figure 2. Scope of spiro[2.4]lactones with variant P411-G8S. ${ }^{a}$ $\mathrm{mM}$ olefin, $5 \mathrm{mM}$ LAD. ${ }^{b}$ Absolute configuration not determined. See SI for details.

With this highly active and selective P411-G8S variant, we next explored the scope of olefin substrates for spiro-lactone construction (Figure 2). Electron-rich styrenyl olefins (1b and 1c) are particularly good substrates, with over 10,000 TTNs. Halides (1e, 1f and $\mathbf{1 h})$ are also well-tolerated, offering opportunities for further derivatization through coupling methods. Fluorinecontaining substrates, despite the strong electron deficiency, are also accepted (e.g., 1g). Additionally, steric bulk (e.g., 2-vinyl naphthalene 1i) did not have a significant influence on reactivity. All tested styrenyl substrates gave (E)-spiro[2.4]lactone products with high-to-perfect stereoselectivity ( 98.6 to $>99.9 \%$ de, and 98.3 to $99.8 \% e e$ ). Unactivated aliphatic olefins such as 4-phenyl butene are also accepted by this biocatalytic system with 1740 TTN. Interestingly, NMR analysis revealed a (Z)-configuration of product $\mathbf{2} \mathbf{j}$, which indicates potentially different binding modes for aromatic vs. aliphatic olefins in the enzyme's active site. The enzymatic reactions are also readily scalable and maintain stereoselectivity and high reactivity. Products $\mathbf{2 b}$ and $\mathbf{2 c}$ were prepared in hundred-milligram quantities with good isolated yields (71\% yield, 6500 TTN and 95\% yield, 6970 TTN). The absolute configurations of products $\mathbf{2} \mathbf{b}$ and $\mathbf{2 f}$ were unambiguously assigned as $(1 S, 2 S)$ by X-ray crystallography. ${ }^{19}$

Having established this biocatalytic platform for the efficient synthesis of spiro-lactones, we speculated that the active-site environment of P411-G8S may be especially suited to stabilize the lactone-carbenoid intermediate. We were eager to examine whether this P411 variant can catalyze the transfer of this lactone-carbene to other functionalities, such as thiols. Carbene $\mathrm{S}-\mathrm{H}$ insertion is poorly developed among carbene-transfer reactions; one challenge is that thiols can poison transition-metal catalysts through coordination. To date, only a few catalytic systems have been developed for asymmetric carbene S-H insertion, and these exhibit limited catalytic efficiency ${ }^{20}$ and/or low stereoselectivity. ${ }^{21}$ Fasan and coworkers reported carbene $\mathrm{S}-\mathrm{H}$ insertion with up to $49 \%$ ee by an engineered myoglobin. ${ }^{7 b}$ Whereas carbene $\mathrm{Si}-\mathrm{H}$ and $\mathrm{N}-\mathrm{H}$ insertions with iron-porphyrin (bio)catalysts have been revealed to undergo concerted $\mathrm{Si}-\mathrm{H}$ insertion ${ }^{22}$ and nucleophilic attack by amine at the carbene center, ${ }^{8 \mathrm{c}}$ the mechanism of carbene $\mathrm{S}-\mathrm{H}$ insertion remains obscure. ${ }^{23}$ We thus decided to take a closer look at lactone-carbene $\mathrm{S}-\mathrm{H}$ insertion with the current enzymatic system.

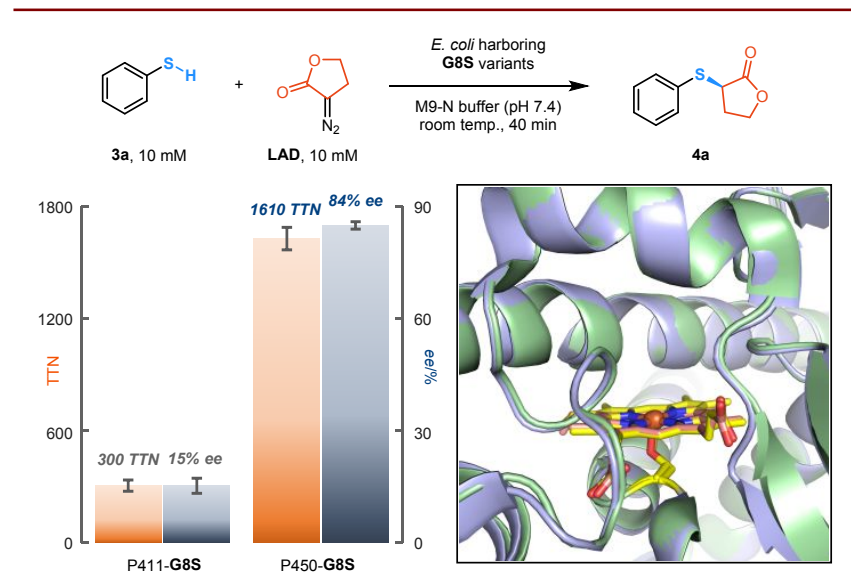

Figure 3. Lactone-carbene $\mathbf{S}-\mathbf{H}$ insertion: comparison of

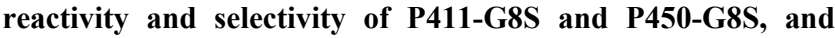
overlay of P450-CIS (PDB: 4h24, in green) and P411-CIS (PDB: 4h23, in purple) active-site structures. Reactions were performed in quadruplicate: suspensions of $E$. coli expressing G8S variants $\left(\mathrm{OD}_{600}=30\right), 10 \mathrm{mM}$ thiol, $10 \mathrm{mM}$ LAD, $25 \mathrm{mM}$ Dglucose and $5 \mathrm{vol} \% \mathrm{EtOH}$ in $\mathrm{M} 9-\mathrm{N}$ buffer at room temperature under anaerobic conditions for 40 minutes.

Using P411-G8S as a whole-cell catalyst, thiophenol 3a reacted with LAD to give the desired $\alpha$-thio- $\gamma$-lactone product $4 \mathbf{a}$ in $300 \pm$ $30 \mathrm{TTN}$, but with poor enantioselectivity $(15 \pm 2 \% e e)$. In an effort to improve reactivity and selectivity, we wanted to explore how the identity of the heme axial ligand affected the $\mathrm{S}-\mathrm{H}$ insertion process. ${ }^{24} \mathrm{We}$ thus tested this reaction with a library of mutant enzymes made by site-saturation mutagenesis of the axial-ligand residue S400 in P411-G8S. To our delight, simply replacing the axial serine with cysteine (the native ligating residue in P450 enzymes) substantially improved reactivity and selectivity, to 1610 \pm 60 TTN and $84 \pm 1 \%$ ee (Figure 3). We next evaluated the substrate range of this cysteine-ligated P450-G8S variant for lactone-carbene $\mathrm{S}-\mathrm{H}$ insertion (Figure 4). Thiophenols with meta$\mathrm{OMe}$ and para-halide substituents were successfully converted into the corresponding $\alpha$-thio- $\gamma$-lactone products ( $4 \mathbf{b}$ to $4 \mathbf{e})$ with good 
TTNs and enantioselectivities. However, para-(fluorinated)alkyl groups (3f to $\mathbf{3 h}$ ) or a bulkier aromatic ring (3j) gave lower reactivity and selectivity, suggesting that steric hindrance may affect substrate orientation. Products $4 \mathbf{d}$ and $4 \mathrm{e}$ were also synthesized in hundred-milligram scale under modified conditions; good isolated yields were obtained, with slightly improved enantioselectivity.

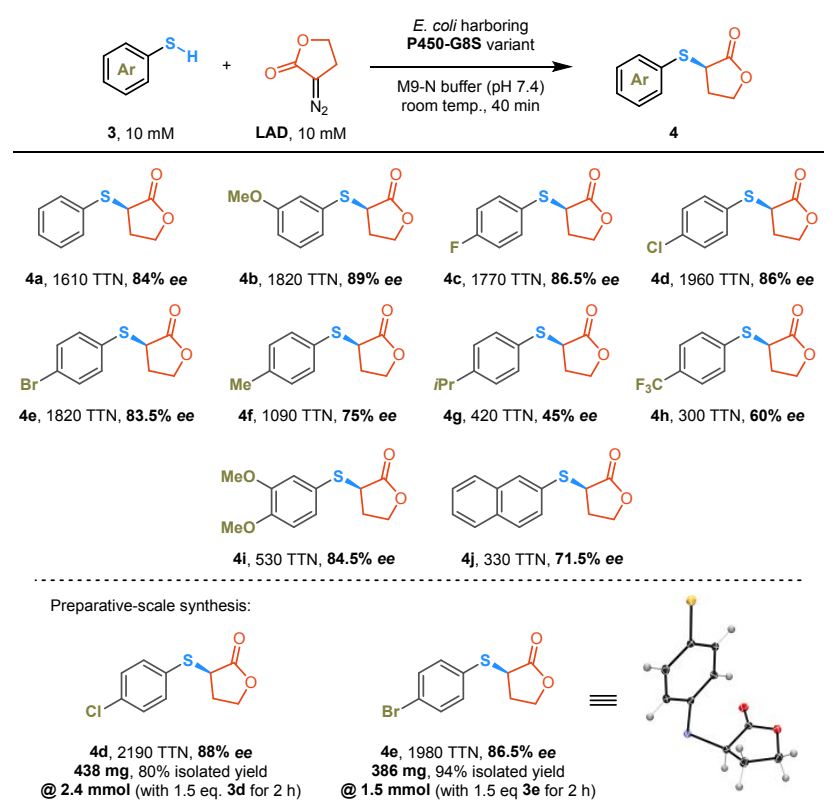

Figure 4. Scope of $\alpha$-thio- $\gamma$-lactones with variant P450-G8S. See SI for details.

It struck us as interesting that the P411/P450-G8S variants behaved so differently in the $\mathrm{S}-\mathrm{H}$ insertion and cyclopropanation reactions. According to a previous structural study of P411-CIS and P450-CIS variants that also differed solely at the axial-ligand residue, the cysteine-to-serine mutation maintains almost identical active-site geometries (Figure 3). As also demonstrated in previous work on in vivo reactions using P411 variants, ${ }^{16}$ the endogenous reductant NADPH can act as an electron donor to reduce $\mathrm{Fe}^{\mathrm{III}}$ to $\mathrm{Fe}^{\mathrm{II}}$, which is required for the iron cofactor to activate diazo compounds to form iron-carbenoid intermediates. Cysteine-ligated heme, on the other hand, has a lower reduction potential of the ferric state and thus results in poor reduction efficiency of the iron center by NADPH. Consequently, P411-G8S exhibits significantly higher cyclopropanation activity compared to P450-G8S, though both show similar selectivities. However, for carbene $\mathrm{S}-\mathrm{H}$ insertion, thiol substrates can also serve as a strong reductant and enable P450 variants to form iron-carbenoids. But this did not explain the significant disparity between P411-G8S and P450-G8S in both reactivity and selectivity, causing us to speculate that the axial ligand was exerting a heretofore unobserved effect on the reaction mechanism.

To explore the effects of axial coordination on the S-H insertion reaction in more detail, we used density functional theory (DFT) calculations. The generation of iron-carbenoid species is reasonably facile, according to previous experimental and computational studies. ${ }^{8 \mathrm{~b}, 8 \mathrm{e}, 22}$ Our computational investigations thus focused on the insertion steps. Simplified iron-porphyrin models (cat1 and cat2) were used, where SMe and OMe were chosen to mimic deprotonated Cys and Ser ligands. ${ }^{25,} 8 \mathrm{f}$

The free energy diagram of the most favorable pathway for S-H insertion is shown in Figure 5. The insertion occurs in a stepwise fashion, involving one hydrogen-atom-transfer (HAT) step and subsequent $\mathrm{C}-\mathrm{S}$ bond formation with a thiyl radical. Both cat1 and cat2 showed similar reactivities for $\mathrm{S}-\mathrm{H}$ bond insertion, with free energy barriers of $19.4 \mathrm{kcal} / \mathrm{mol}$ and $18.5 \mathrm{kcal} / \mathrm{mol}$, respectively. However, we found that the iron-alkyl intermediates (int3 and int10) can undergo a reversible $\mathrm{C}-\mathrm{Fe}$ bond homolytic cleavage (via TS6 and TS12), which erodes the enantioenriched alkyl-substituted stereocenter. The two pathways, radical rebound and $\mathrm{C}-\mathrm{Fe}$ bond cleavage, are differentiated by the axial coordination. With $\mathrm{SMe}$ ligation, $\mathrm{C}-\mathrm{S}$ bond formation is more favorable than $\mathrm{C}-\mathrm{Fe}$ bond homolytic cleavage $\left(\mathbf{T S} 4, \Delta \mathrm{G}^{\neq}=6.7 \mathrm{kcal} / \mathrm{mol} v s\right.$. TS6, $\Delta \mathrm{G}^{\neq}=10.4$ $\mathrm{kcal} / \mathrm{mol}$ ), while the opposite is true for the OMe-ligated intermediate int10 (TS11, $\Delta \mathrm{G}^{\neq}=7.3 \mathrm{kcal} / \mathrm{mol} v \mathrm{~s}$. TS12, $\Delta \mathrm{G}^{\neq}=6.2$ $\mathrm{kcal} / \mathrm{mol}$ ). These results indicate that Cys-ligated P450 enzymes should achieve much higher enantioselectivities than Ser-ligated P411 enzymes, which matches the experimental observations.

The axial coordination has a limited effect on $\mathrm{C}-\mathrm{S}$ rebound, but strongly controls the feasibility of $\mathrm{C}-\mathrm{Fe}$ bond dissociation. ${ }^{26}$ Since oxygen has a much higher electronegativity than sulfur, the anionic cat2 is more stable than the sulfur-coordinated cat1. Therefore, CFe homolytic cleavage with OMe ligation, which releases cat2, has a lower activation barrier and is more exothermic than that with sulfur coordination. The difference in exothermicity drives the change in reaction barrier, which eventually leads to the difference in enantioselectivities of the two catalysts.

In conclusion, we have developed a powerful biocatalytic platform based on engineered cytochrome P411/P450 enzymes that enables facile access to a broad array of structurally diverse $\gamma$ lactone derivatives including spiro[2.4]lactones and $\alpha$-thio- $\gamma$ lactones. This convergent biosynthetic scheme offers a succinct method to construct complex lactone-based structures, as an alternative to nature's strategy of de novo assembly of lactone moieties. Interestingly, by simply altering the heme ligation (serine or cysteine) in the cytochrome P450 variants, we were able to rapidly optimize the two carbene-transfer reactions, cyclopropanation and $\mathrm{S}-\mathrm{H}$ insertion, with unprecedented levels of efficiency and stereo-control. To understand how axial ligation affects both selectivity and reactivity in carbene $\mathrm{S}-\mathrm{H}$ insertion, we conducted a DFT study and described two mechanistic pathways involving a radical coupling process between a thiyl radical and a heme-bound alkyl species or a free alkyl radical. The different electronic properties of serine and cysteine ligands lead to opposite preferences in the reaction pathways, and distinct product profiles. The development of novel reactions combined with thorough mechanistic analyses expands the biocatalytic repertoire of hemeproteins and also provides insights into how these enzymes can be tuned for further exploration of new chemistries. 


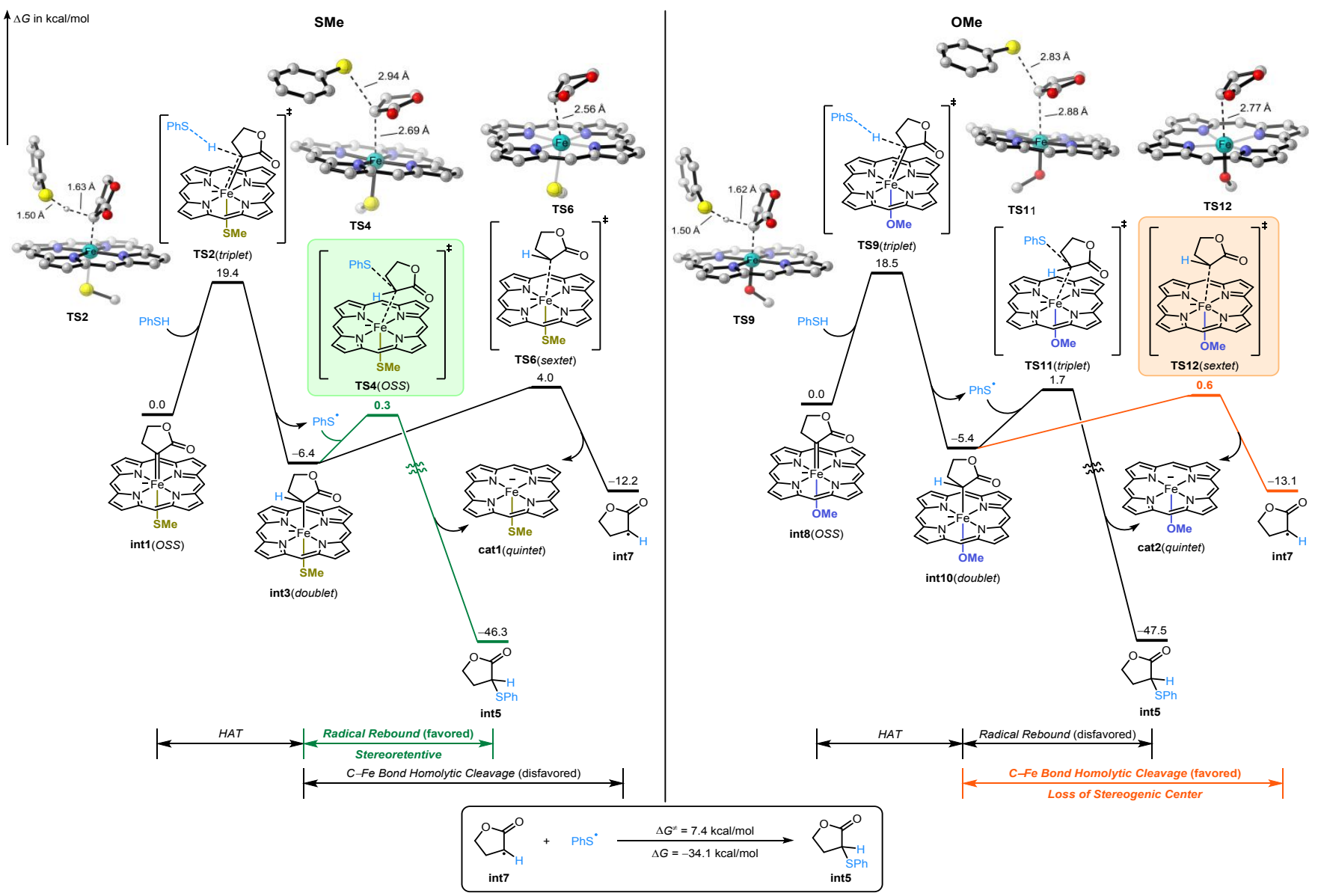

Figure 5. Free energy diagram for the most favorable reaction pathways of $\mathbf{S}-\mathbf{H}$ insertion. Gibbs free energy obtained at the B3LYP/def2-TZVP//B3LYP/6-31G(d)-LANL2DZ level. The most stable spin states are shown in parentheses. OSS is open-shell singlet.

\section{ASSOCIATED CONTENT}

\section{Supporting Information}

Experimental details, and spectral data for all new compounds. This material is available free of charge via the Internet at http://pubs.acs.org.

\section{AUTHOR INFORMATION}

\section{Corresponding Author}

hxchem@zju.edu.cn (X.H.) and frances@cheme.caltech.edu (F.H.A.)

\section{ORCID}

Kai Chen: 0000-0002-3325-3536

Shuo-Qing Zhang: 0000-0002-7617-3042

Oliver F. Brandenberg: 0000-0001-5662-1234

Xin Hong: 0000-0003-4717-2814

Frances H. Arnold: 0000-0002-4027-364X

\section{Author Contributions}

${ }^{\dagger}$ K.C. and S.-Q.Z. contributed equally.

\section{Notes}

The authors declare no competing financial interests.

\section{ACKNOWLEDGMENT}

Financial support by NSF Division of Molecular and Cellular Biosciences grant MCB-1513007, National Natural Science Foundation of China (21702182), Zhejiang University, the Chinese
"Thousand Youth Talents Plan", and the "Fundamental Research Funds for the Central Universities" is gratefully acknowledged. O.F.B. acknowledges support from the Swiss National Science Foundation (P300PA_171225). Calculations were performed on the high-performance computing system at the Department of Chemistry, Zhejiang University. We thank X. Huang, D. K. Romney, R. K. Zhang, S. B. J. Kan, R. D. Lewis in the Arnold lab and M. Garcia-Borràs in the K. Houk Lab, UCLA for helpful discussion and comments. We also thank N. Torian and the Caltech Mass Spectrometry Laboratory, and L. M. Henling and the Caltech X-ray Crystallography Facility for analytical support, and B. M. Stoltz for use of a polarimeter.

\section{REFERENCES AND NOTES}

(1) Ortiz de Montellano, P. R. ed., Cytochrome P450: structure, mechanism, and biochemistry (Springer International Publishing: Cham, 2015)

(2) Poulos, T. L. Heme enzyme structure and function. Chem. Rev. 2014, 114, 3919-3962.

(3) Brandenberg, O. F.; Fasan, R.; Arnold, F. H. Exploiting and engineering hemoproteins for abiological carbene and nitrene transfer reactions. Curr. Opin. Biotechnol. 2017, 47, 102-111.

(4) Prier, C. K.; Arnold, F. H. Chemomimetic biocatalysis: Exploiting the synthetic potential of cofactor-dependent enzymes to create new catalysts. J. Am. Chem. Soc. 2015, 137, 13992-14006.

(5) Zhang, R. K.; Romney, D. K.; Kan, S. B. J.; Arnold, F. H. Chapter 5 in Dieguez, M.; Bäckvall, J.-E.; Pamies, O. eds, Artificial Metalloenzymes and MetalloDNAzymes in Catalysis. From Design to Applications (Wiley$\mathrm{VCH}$, Weinheim, 2018).

(6) Examples of hemeprotein-catalyzed carbene addition to olefins and alkynes: a) Coelho, P. S.; Brustad, E. M.; Kannan, A.; Arnold, F. H. Olefin 
cyclopropanation via carbene transfer catalyzed by engineered cytochrome P450 enzymes. Science 2013, 339, 307-310. b) Wang, Z. J.; Renata, H.; Peck, N. E.; Farwell, C. C.; Coelho, P. S.; Arnold, F. H. Improved cyclopropanation activity of histidine-ligated cytochrome $\mathrm{P} 450$ enables the enantioselective formal synthesis of levomilnacipran. Angew. Chem. Int. Ed. 2014, 53, 6810-6813. c) Hernandez, K. E.; Renata, H.; Lewis, R. D.; Kan, S. B. J.; Zhang, C.; Forte, J.; Rozzell, D.; McIntosh, J. A.; Arnold, F. H. Highly stereoselective biocatalytic synthesis of key cyclopropane intermediate to ticagrelor. ACS Catal. 2016, 6, 7810-7813. d) Knight, A M.; Kan, S. B. J.; Lewis, R. D.; Brandenberg, O. F.; Chen, K.; Arnold, F. $\mathrm{H}$. Diverse engineered heme proteins enable stereodivergent cyclopropanation of unactivated alkenes. ACS Cent. Sci. 2018, 4, 372-377. e) Chen, K.; Huang, X.; Kan, S. B. J.; Arnold, F. H. Enzymatic construction of highly strained carbocycles. Science 2018, 360, 71-75. f) Bordeaux, M.; Tyagi, V.; Fasan, R. Highly diastereoselective and enantioselective olefin cyclopropanation using engineered myoglobin-based catalysts. Angew. Chem. Int. Ed. 2015, 54, 1744-1748.

(7) Examples of hemeprotein-catalyzed carbene insertion into $\mathrm{X}-\mathrm{H}$ bonds: a) Wang, Z. J.; Peck, N. E.; Renata, H.; Arnold, F. H. Cytochrome $\mathrm{P} 450$-catalyzed insertion of carbenoids into $\mathrm{N}-\mathrm{H}$ bonds. Chem. Sci. 2014, 5, 598-601. b) Tyagi, V.; Bonn, R.B.; Fasan, R. Intermolecular carbene S$\mathrm{H}$ insertion catalysed by engineered myoglobin-based catalysts. Chem. Sci. 2015, 6, 2488-2494. c) Kan, S. B. J.; Lewis, R. D.; Chen, K.; Arnold, F. H. Directed evolution of cytochrome $\mathrm{c}$ for carbon-silicon bond formation: Bringing silicon to life. Science 2016, 354, 1048-1051. d) Kan, S. B. J.; Huang, X.; Gumulya, Y.; Chen, K.; Arnold, F. H. Genetically programmed chiral organoborane synthesis. Nature 2017, 552, 132-136.

(8) Mechanistic studies on iron-porphyrin-catalyzed carbene-transfer chemistries: a) Khade, R. L.; Fan, W.; Ling, Y.; Yang, L.; Oldfield, E.; Zhang, Y. Iron porphyrin carbenes as catalytic intermediates: Structures, Mössbauer and NMR spectroscopic properties, and bonding. Angew. Chem., Int. Ed. 2014, 53, 7574-7578. b) Khade, R. L.; Zhang, Y. Catalytic and biocatalytic iron porphyrin carbene formation: Effects of binding mode, carbene substituent, porphyrin substituent, and protein axial ligand. $\mathrm{J}$. Am. Chem. Soc. 2015, 137, 7560-7563. c) Sharon, D. A.; Mallick, D.; Wang, B.; Shaik, S. Computation sheds insight into iron porphyrin carbenes' electronic structure, formation, and $\mathrm{N}-\mathrm{H}$ insertion reactivity. J. Am. Chem. Soc. 2016, 138, 9597-9610. d) Wei, Y.; Tinoco, A.; Steck, V.; Fasan, R.; Zhang, Y. Cyclopropanations via heme carbenes: Basic mechanism and effects of carbene substituent, protein axial ligand, and porphyrin substitution. J. Am. Chem. Soc. 2018, 140, 1649-1662. e) Li, Y.; Huang, J.S.; Zhou, Z.-Y.; Che, C.-M.; You, X.-Z. Remarkably stable iron porphyrins bearing nonheteroatom-stabilized carbene or (alkoxycarbonyl)carbenes: Isolation, X-ray crystal structures, and carbon atom transfer reactions with hydrocarbons. J. Am. Chem. Soc. 2002, 124, 13185-13193. f) Su, H.; Ma, G.; Liu, Y. Theoretical insights into the mechanism and stereoselectivity of olefin cyclopropanation catalyzed by two engineered cytochrome P450 enzymes. Inorg. Chem. 2018, 57, 11738-11745.

(9) a) Kara, S.; Spickermann, D.; Schrittwieser, J. H.; Weckbecker, A.; Leggewie, C.; Arends, I. W. C. E.; Hollmann, F. Access to lactone building blocks via horse liver alcohol dehydrogenase-catalyzed oxidative lactonization. ACS Catal. 2013, 3, 2436-2439. b) Morrill, C.; Jensen, C.; Just-Baringo, X.; Grogan, G.; Turner, N. J.; Procter, D. J. Biocatalytic conversion of cyclic ketones bearing $\alpha$-quaternary stereocenters into lactones in an enantioselective radical approach to medium-sized carbocycles. Angew. Chem., Int. Ed. 2018, 57, 3692-3696. c) Serra, S.; Fuganti, C.; Brenna, E. Biocatalytic preparation of natural flavours and fragrances. Trends Biotechnol. 2005, 23, 193-198.

(10) a) Moore, T.; Adhikari, R.; Gunatillake, P. Chemosynthesis of bioresorbable poly( $\gamma$-butyrolactone $)$ by ring-opening polymerisation: a review. Biomaterials, 2005, 26, 3771-3782. b) Delgove, M. A. F.; Elford, M. T.; Bernaerts, K. V.; De Wildeman, S. M. A. Toward upscaled biocatalytic preparation of lactone building blocks for polymer applications. Org. Process Res. Dev. 2018, 22, 803-812.

(11) a) Piotrowski, D. W. Mineralocorticoid receptor antagonists for the treatment of hypertension and diabetic nephropathy. J. Med. Chem. 2012, 55, 7957-7966. b) Pommier, Y.; Schwartz, R. E.; Zwelling, L. A.; Kohn, $\mathrm{K}$. W. Effects of DNA intercalating agents on topoisomerase II induced DNA strand cleavage in isolated mammalian cell nuclei. Biochemistry 1985, 24, 6406-6410.

(12) a) DeAngelis, A.; Dmitrenko, O.; Fox, J. M. Rh-catalyzed intermolecular reactions of cyclic $\alpha$-diazocarbonyl compounds with selectivity over tertiary C-H bond migration. J. Am. Chem. Soc. 2012, 134, 11035-11043. b) Sattely, E. S.; Meek, S. J.; Malcolmson, S. J.; Schrock, R. R.; Hoveyda, A. H. Design and stereoselective preparation of a new class of chiral olefin metathesis catalysts and application to enantioselective synthesis of quebrachamine: Catalyst development inspired by natural product synthesis. J. Am. Chem. Soc. 2009, 131, 943-953.

(13) DeAngelis, A.; Panish, R.; Fox, J. M. Rh-catalyzed intermolecular reactions of $\alpha$-alkyl- $\alpha$-diazo carbonyl compounds with selectivity over $\beta$ hydride migration. Acc. Chem. Res. 2016, 49, 115-127.

(14) Quasdorf, K. W.; Overman, L. E. Catalytic enantioselective synthesis of quaternary carbon stereocentres. Nature 2014, 516, 181-191.

(15) a) Christoffers, J.; Baro, A. eds. Quaternary Stereocenters: Challenges and Solutions for Organic Synthesis (Wiley-VCH, Weinheim, 2005). b) Liu, Y.; Han, S.-J.; Liu, W.-B.; Stoltz, B. M. Catalytic enantioselective construction of quaternary stereocenters: Assembly of key building blocks for the synthesis of biologically active molecules. Acc. Chem. Res. 2015, 48, 740-751.

(16) Coelho, P. S.; Wang, Z. J.; Ener, M. E.; Baril, S. A.; Kannan, A.; Arnold, F. H.; Brustad, E. M. A serine-substituted P450 catalyzes highly efficient carbene transfer to olefins in vivo. Nat. Chem. Bio. 2013, 9, 485487.

(17) Brandenberg, O. F.; Prier, C. K.; Chen, K.; Knight, A. M.; Wu, Z.; Arnold, F. H. Stereoselective enzymatic synthesis of heteroatomsubstituted cyclopropanes. ACS Catal. 2018, 8, 2629-2634.

(18) Here we use the name P411-G8S to refer to this P411 variant instead of its initial name $\mathrm{P} 411-\mathrm{VAC}_{c i s}$ in ref 17.

(19) Crystallographic coordinates and structure factors have been deposited with the Cambridge Crystallographic Data Centre (www.ccdc.cam.ac.uk) under reference number 1864173, 1864172 and 1864174 for compound $\mathbf{2 b}, \mathbf{2 f}$ and $\mathbf{4 e}$.

(20) Zhang,Y.-Z.; Zhu, S.-F.; Cai, Y.; Mao, H.-X.; Zhou, Q.-L. Coppercatalyzed enantioselective carbenoid insertion into S-H bonds. Chem. Commun. 2009, 5362-5364.

(21) Limited examples of asymmetric carbene S-H insertion, but with $<$ $30 \%$ ee: a) Brunner, H.; Wutz, K.; Doyle, M. P. Enantioselective S-H and $\mathrm{C}-\mathrm{H}$ insertions with optically active $\mathrm{Rh}(\mathrm{II})$ and $\mathrm{Cu}(\mathrm{II})$ catalysts. Asymmetric catalysis, LVIII. Monatsh. Chem. 1990, 121, 755-764. b) Galardon, E.; Roué, S.; Maux, P. L.; Simonneaux, G. Asymmetric cyclopropanation of alkenes and diazocarbonyl insertion into S-H bonds catalyzed by a chiral porphyrin Ru(II) complex. Tetrahedron Lett. 1998, 39, 2333-2334. c) Zhang, X.-M.; Ma, M.; Wang, J.-B. Catalytic asymmetric S$\mathrm{H}$ insertion reaction of carbenoids. Arkivoc, 2003, 2003, 84-91. d) Yang, H.; Swartz, A. M.; Srivastava, P.; Ellis-Guardiola, K.; Park, H. J.; Upp, D.; Belsare, K.; Lee, G.; Zhang, C.; Moellering, R. E.; Lewis, J. C. Evolving artificial metalloenzymes via random mutagenesis. Nat. Chem. 2018, 10, 318-324.

(22) Lewis, R. D.; Garcia-Borràs, M.; Chalkley, M. J.; Buller, A. R.; Houk, K. N.; Kan, S. B. J.; Arnold, F. H. Catalytic iron-carbene intermediate revealed in a cytochrome c carbene transferase. Proc. Natl. Acad. Sci. USA 2018, 115, 7308-7313.

(23) Rhodium-catalyzed carbene $\mathrm{S}-\mathrm{H}$ insertion via sulfonium ylide formation: Xu, B.; Zhu, S.-F.; Zhang, Z.-C.; Yu, Z.-X.; Ma, Y.; Zhou, Q.L. Highly enantioselective S-H bond insertion cooperatively catalyzed by dirhodium complexes and chiral spiro phosphoric acids. Chem. Sci. 2014, $5,1442-1448$

(24) Examples of tuning catalysis through changing axial ligands: a) ref 6b. b) ref 16. c) Hayashi T.; Tinzl M.; Mori T.; Krengel U.; Proppe J.; Soetbeer J.; Klose D.; Jeschke G.; Reiher M.; Hilvert D. Capture and characterization of a reactive haem-carbenoid complex in an artificial metalloenzymes. Nat. Catal. 2018, 1, 578-584. d) Key, H. M.; Dydio, P.; Clark, D. S.; Hartwig, J. F. Abiological catalysis by artificial haem proteins containing noble metals in place of iron. Nature 2016, 534, 534-537. e) Moore, E. J.; Steck, V.; Bajaj, P.; Fasan, R. Chemoselective cyclopropanation over carbene $\mathrm{Y}-\mathrm{H}$ insertion catalyzed by an engineered carbene transferase. J. Org. Chem. 2018, 83, 7480-7490.

(25) Neutral ligands were found prone to deprotonation, see SI for details.

(26) Metalloporphyrin-catalyzed $\mathrm{C}-\mathrm{H}$ functionalizations through HAT followed by radical rebound or radical coupling after dissociation: a) Cho, K.-B.; Hirao, H.; Shaik, S.; Nam, W. To rebound or dissociate? This is the mechanistic question in $\mathrm{C}-\mathrm{H}$ hydroxylation by heme and nonheme metaloxo complexes. Chem. Soc. Rev. 2016, 45, 1197-1210. b) Liu, W.; Groves, J. T. Manganese Catalyzed C-H Halogenation. Acc. Chem. Res. 2015, 48, 1727-1735. c) Liu, W.; Cheng, M.-J.; Nielsen, R. J.; Goddard, W. A.; Groves, J. T. Probing the $\mathrm{C}-\mathrm{O}$ bond-formation step in metalloporphyrincatalyzed C-H oxygenation reactions. ACS Catal. 2017, 7, 4182-4188. 
Table of Contents (TOC)

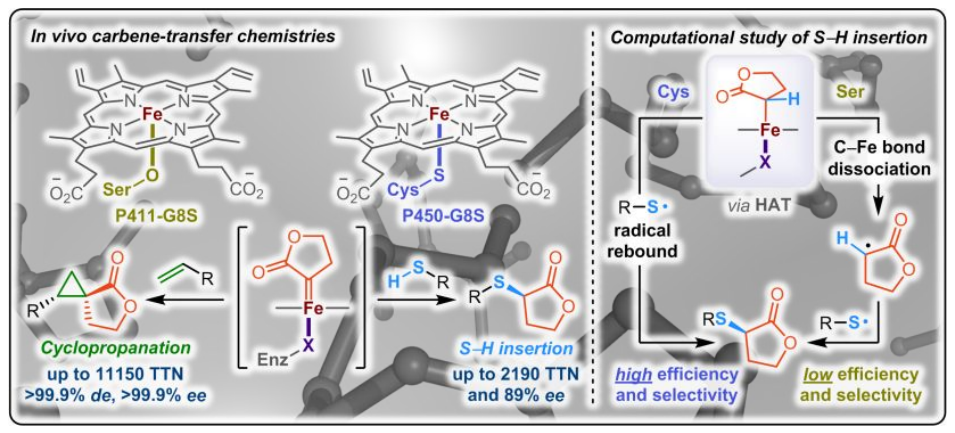

